\title{
Quality of Life of Patients With Heart Failure at Teaching Hospitals in Erbil City
}

Berivan Star Hammad Ameen; Department of Nursing, College of Nursing, Hawler Medical University, Erbil, Iraq. (Correspondence: berivan.hamadameen@hmu.edu.krd)

Yousif Mohammed Younis; Department of Nursing, College of Nursing, Hawler Medical University, Erbil, Iraq.

\begin{abstract}
Background and objectives: Heart Failure is a common and significant health problem, with an increasing incidence and a gloomy prognosis that is often accompanied by a negative impact on the length and quality of life of patients. This study aimed to assess quality of life among patients with heart failure in Erbil city and to find the association of quality of life domains (physical, level of independence and social relationship) with some sociodemographic data (age, gender, level of education, and marital status)

Methods: A quantitative design / a descriptive cross-sectional study was conducted at Hawler and Rizgary Teaching Hospitals in Erbil city Kurdistan region. This study was carried out from November 17th 2014 to November 17th 2015 on non-probability (purposive) samples was selected among 140 heart failure patients who were admitted to coronary care unit and medical ward of both teaching hospitals. Their quality of life was measured by standardized questionnaire of world health organization with some modification.

Results: The findings of the study indicated that most patients were Female and Illiterate, their mean age was 68.75. Moreover, significant associations exist between levels of education with physical ability, level of independence, social domains, and marital state with physical domain.
\end{abstract}

Conclusion: The study concluded that the majority of the study sample had moderate level of quality of life while less than one-fourth of them had poor level.

Keywords: Heart failure, Quality of life, Coronary care unit, World health organization

Received: 5/1/2019

Accepted: 22/9/2019

Published: 30/11/2019

\section{INTRODUCTION}

Heart failure (HF) is an imprecise term used to describe the state that develops when the heart cannot maintain an adequate cardiac output or can do so only at the expense of an elevated filling pressure. . Cardiac output is adequate at rest and becomes inadequate only when the metabolic demand increases during exercise or some other form of stress $[1,2]$. Some cases of HF are reversible, depending on the cause. Most often, HF is a progressive, lifelong condition that is managed with lifestyle changes and medications to prevent episodes of acute decompensate heart failure. These episodes are characterized by an increase in symptoms but decreased in cardiac output, and low perfusion [3]. World Health Organization Quality of Life (WHOQOL) Group defined Quality of Life as an "individual's perception" of their position in life in the context of the culture and value systems in which they live and in relation to their goals, expectations, standards and concerns. It is a broad ranging concept affected in a complex way by the person's physical health, 
psychological state, personal belief, social relationships, and their relationship to salient features of their environment [4]. Heart failure is a major public health problem in industrialized nations. It seems to be the only common cardiovascular condition, which is increasing in prevalence and incidence in North America and Europe. In the United States, HF is responsible for 1 million hospital admissions and 50,000 deaths annually [5]. The incidence of HF increases with age. American Heart Association estimate more than 5 million people in the United States have HF, and 550,000 new cases are diagnosed each year $[3,6]$. Heart failure is a serious and chronic condition whose prevalence $(0.2-0.4 \%$ in the general population and up to $17 \%$ in people over 70 years of age) continues to increase its incidence is calculated to be around 0.2$0.3 \%$ per year. The estimated prevalence of $\mathrm{HF}$ in India is 1.3-4.6 million with an annual incidence of 0.5-1.8 million, in China, the $\mathrm{HF}$ prevalence rate among the general population was $0.9 \%[7,8]$. There were $(509)$ cases of heart failure in Erbil city in (2013) according to the statistics of Directorate of Health in Erbil. Coronary artery diseases and advancing age are the primary risk factors for CHF, other factors including hypertension, diabetes, cigarette smoking, obesity, and high cholesterol level can contribute the factors to the development of Heart failure [9].Causes of heart failure include coronary artery disease, myocardial infarction, cardiomyopathy, heart valve problems, and hypertension $[10,11]$. Heart failure is a most frequent cause of hospitalization for people aged 65 and older. Currently, HF continues to have a poor prognosis and is likely to remain a major clinical and health care problem [9]. a measure of QOL requires a definition of the concept. QOL theoretically encompasses the individual's physical health, psychosocial wellbeing and functioning, independence, control over life material circumstances, and external environment. Health related to quality of life health related quality of life (HRQL) "the functional effect of an illness and its consequent therapy upon a patient, as perceived by the patient [12]. Heart failure is one of the chronic diseases that mainly affect quality of life. The physical condition of patients is compromised be dyspnea, fatigue and loss of muscular mass, and commonly by symptoms of the underlying cause of their condition (e.g. angina). In addition, dietary restrictions, difficulties in executing occupational and family responsibilities, progressive loss of self-reliance and self-control, the side effects of medication, and recurrent hospitalizations are also taken into consideration, and it is easy to understand how the quality of life of these patients can deteriorate [13].Decreased functional capacity and psychological deterioration in end-stage HF patients may have a negative impact on the quality of life. Functional inability to perform activities is one of the most common problems in patients with HF. Functional impairment has a stronger association with quality of life in HF patients than cardiac function does [14]. Heart failure is one of the chronic diseases that mainly affects quality of life, which is leading to compromised physical activities of daily living of patient, thus to preventing and to controlling of heart failure take much attention in Kurdistan to reduce mortality and morbidity of heart failure. This study aimed to assess the quality of life in patients with heart failure in Erbil city and to find out the association of quality of life domains (physical, level of independence and social relationship) with some socio-demographic data (age, gender, level of education, and marital status). 


\section{METHODS}

Descriptive cross-sectional study design was conducted to assess the quality of life of patients with heart failure in Erbil City. Among non-probability (purposive) samples of 140 adult patients with heart failure who were admitted to the Coronary Care Unit and medical wards in both Hawler and Rizgary Teaching Hospitals. The study started from November 17th 2014 to November 17th 2015. Approval was obtained from ethical committee in Nursing College / Hawler Medical University. The study was carried out after providing approval by General Director of Health in Erbil (DOH), Hawler and Rizgary Teaching Hospitals, oral consent was taken from research participants. Inclusion criteria for selecting the samples of the study included patients who agrees to participate in the study. Patients aged more than 18 years, diagnosed with heart failure, conscious patient, both gender and patients who had psychiatric disorders and patient's diagnosis before 3 month of heart failure were excluded. The data was collected through the interview method questionnaire. It was developed by researcher and adopted with revised from WHO regarding quality of life, Data were gathered through the using of questionnaire which consisted of following parts:

Part one,Demographic data:

It was concerned with demographic characteristics of the patients such as age, gender, marital status, level of education, residential area occupation before and after diagnosis disease.

Part two:

Overall of QOL and associations between patients age group and QOL domains, patients' gender and QOL domains, patients' level of education QOL domains, patient's marital status QOL domains. The calculation of overall quality of life was categorized to three groups of good quality of life, fair quality of life, and poor quality of life.
The data were analyzed using of (SPSS Windows Software Version 20). Data analysis approach for this study included two approaches: Descriptive data analysis approach includes (Frequency and Percentage) and inferential statistical data analysis approach includes (Chi-square and Fisher's Exact Test).

\section{RESULTS}

Table 1 shows the distribution of the sociodemographic characteristics of 140 adult heart failure patients. The age of the patients ranged from $25-\geq 65$ years. The highest percentage $68.7 \%$ of the samples were in the age group $\geq 65$ years. $60.7 \%$ of them were female. It was shown that the highest percentage $72.8 \%$ were illiterate. The majority $58.6 \%$ of the samples were married for $61.5 \%$, in regard to residential area, the highest percentage of the samples were from urban. Moreover, the highest percentage $54.4 \%$ were reported housewife. In addition, $60 \%$ were out of work, the rest $40 \%$ returned to work after diagnosis of their disease. Table 2 shows overall level of quality of life of HF patients among $140 \mathrm{HF}$ patients. The highest percentage (75.7\%) of patients had fair level of $\mathrm{QOL}$ and (13.6\%) of patients had poor level of QOL while (10.7\%) had good level of QOL. Table 3 shows the association between age group and quality of life domains, the highest percentage $(68.7 \%)$ of the patient's age was age group $\geq 65$ years and the lowest percentage $(0.7 \%)$ was inage group $25-34$ years. The finding of the study showed that there was no significant relationship between patients' age group and the rest of other quality of life domains including physical $P=0.56$, level of independence $P=0.31$, and social $P=0.76$ domains. 
Table 1. Socio-demographic characteristics of heart failure patients

\begin{tabular}{|c|c|c|c|}
\hline \multicolumn{2}{|c|}{ Socio-demographic characteristics } & \multirow[t]{2}{*}{$\mathbf{F}$} & \multirow[t]{2}{*}{$(\%)$} \\
\hline Age group / years & & & \\
\hline & $25-34$ & 1 & $(0.7)$ \\
\hline & $35-44$ & 3 & (2.1) \\
\hline & $45-54$ & 16 & $(11.4)$ \\
\hline & $55-64$ & 24 & $(17.1)$ \\
\hline & $\geq 65$ & 96 & (68.7) \\
\hline & Total & 140 & $(100)$ \\
\hline \multicolumn{4}{|l|}{ Gender } \\
\hline & Male & 55 & (39.3) \\
\hline & Female & 85 & $(60.7)$ \\
\hline & Total & 140 & $(100)$ \\
\hline \multirow[t]{6}{*}{ Educational level } & Illiterate & 102 & (72.8) \\
\hline & Able to read and write & 21 & (15) \\
\hline & Primary school graduate & 11 & (7.9) \\
\hline & Secondary school graduate & 4 & (2.9) \\
\hline & College graduate & 2 & $(1.4)$ \\
\hline & Total & 140 & $(100)$ \\
\hline \multicolumn{4}{|l|}{ Marital status } \\
\hline & Single & 2 & $(1.4)$ \\
\hline & Married & 86 & (61.5) \\
\hline & Divorced & 3 & (2.1) \\
\hline & Widowed & 48 & (34.3) \\
\hline & Separated & 1 & $(0.7)$ \\
\hline & Total & 140 & $(100)$ \\
\hline \multicolumn{4}{|l|}{ Residential area } \\
\hline & Rural & 58 & (41.4) \\
\hline & Urban & 82 & $(58.6)$ \\
\hline & Total & 140 & (100) \\
\hline \multicolumn{4}{|l|}{ Occupation before } \\
\hline & Employed & 17 & (12.1) \\
\hline \multirow[t]{4}{*}{ disease } & Unemployed & 31 & (22.1) \\
\hline & Housewife & 76 & (54.4) \\
\hline & Retired & 16 & (11.4) \\
\hline & Total & 140 & (100) \\
\hline \multicolumn{4}{|l|}{ Occupation after } \\
\hline & Returned to work & 56 & (40) \\
\hline \multicolumn{4}{|l|}{ Lower case } \\
\hline & Out of work & 84 & (60) \\
\hline & Total & 140 & $(100)$ \\
\hline
\end{tabular}


Table 2: Overall levels of quality of life domains of heart failure patients

\begin{tabular}{lll}
\hline Overall Quality of Life & $\mathbf{F}$ & $(\%)$ \\
\hline Good & 15 & $(10.7)$ \\
Fair & 106 & $(75.7)$ \\
Poor & 19 & $(13.6)$ \\
Total & $\mathbf{1 4 0}$ & $(\mathbf{1 0 0 )}$ \\
\hline
\end{tabular}

Table 3. Association between patients' age group and quality of life domains of heart failure patients

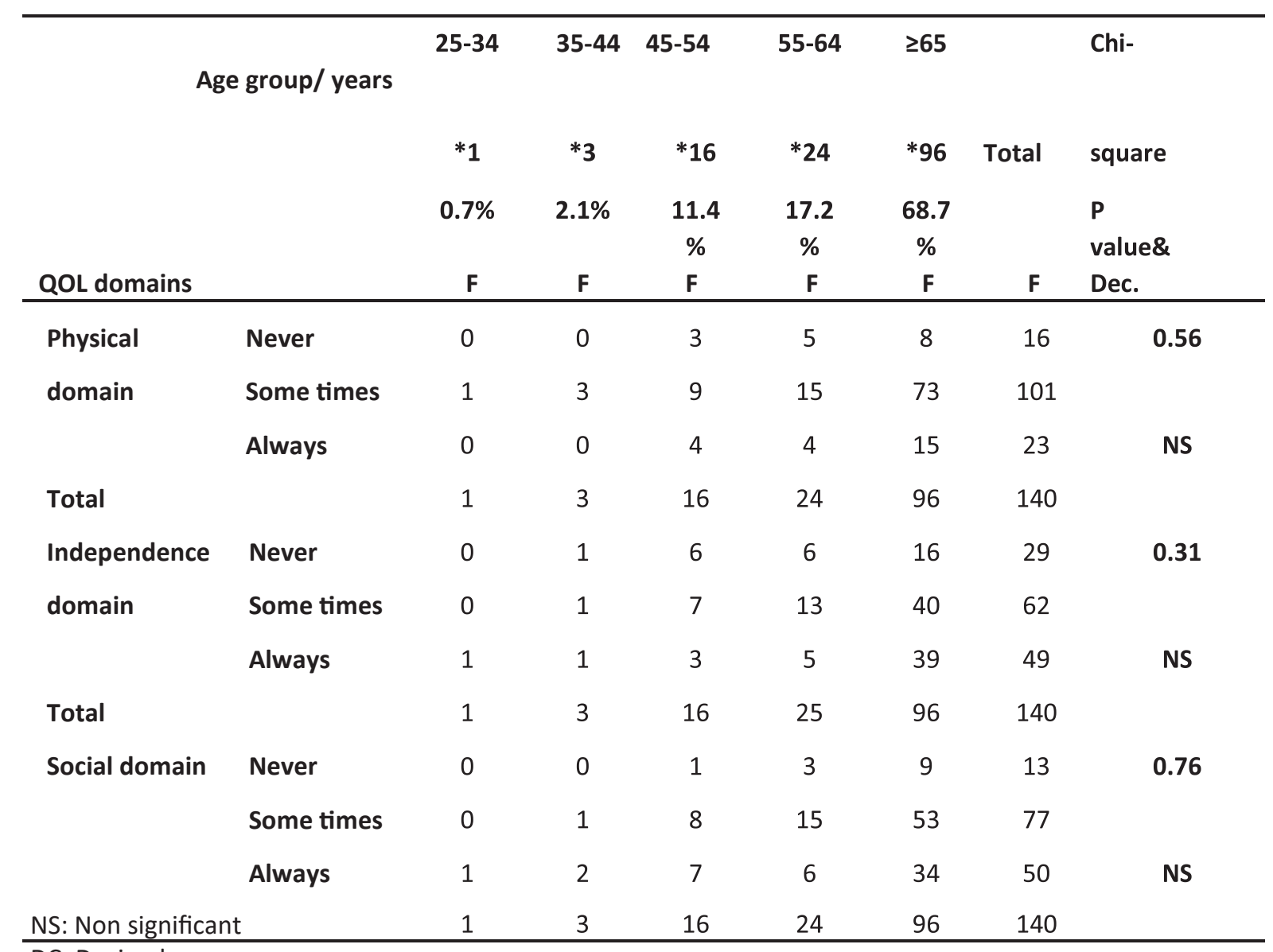

DC: Decimal

Table 4 illustrates the associations between gender and quality of life domains of HF patients. Concerning gender, the highest percentage $(60.7 \%)$ of patients was female. This table shows there was no significant relationship between gender and quality of life domains, physical $\mathrm{P}=0.92$, level of independence $\mathrm{P}=0.26$, and social $P=0.99$. Table 5 shows the association between levels of education and quality of life domains of HF patients. Regarding levels of education, the majority of patients $(72.8 \%)$ were illiterate. The results found that there was a highly significant relationship between patients' levels of education and levels of independence $p=0.009$, significant relationship with physical $p=0.012$ and social domain $p=0.05$. Table 6. Association between patients 'marital status and quality of life domains. Table 6 shows the association between marital statues and $\mathrm{QOL}$ domains. It has indicated that the highest numbers of the sample (61.5\%) were 
married. The results have also shown that there was significant relationship between the marital status and physical 0.01. While there was no significant relationship between patients' marital status and QOL in level of independence, and social domain $0.24,0.7$ respectively.

Table.4 Association between patients' gender and quality of life domains of heart failure patients

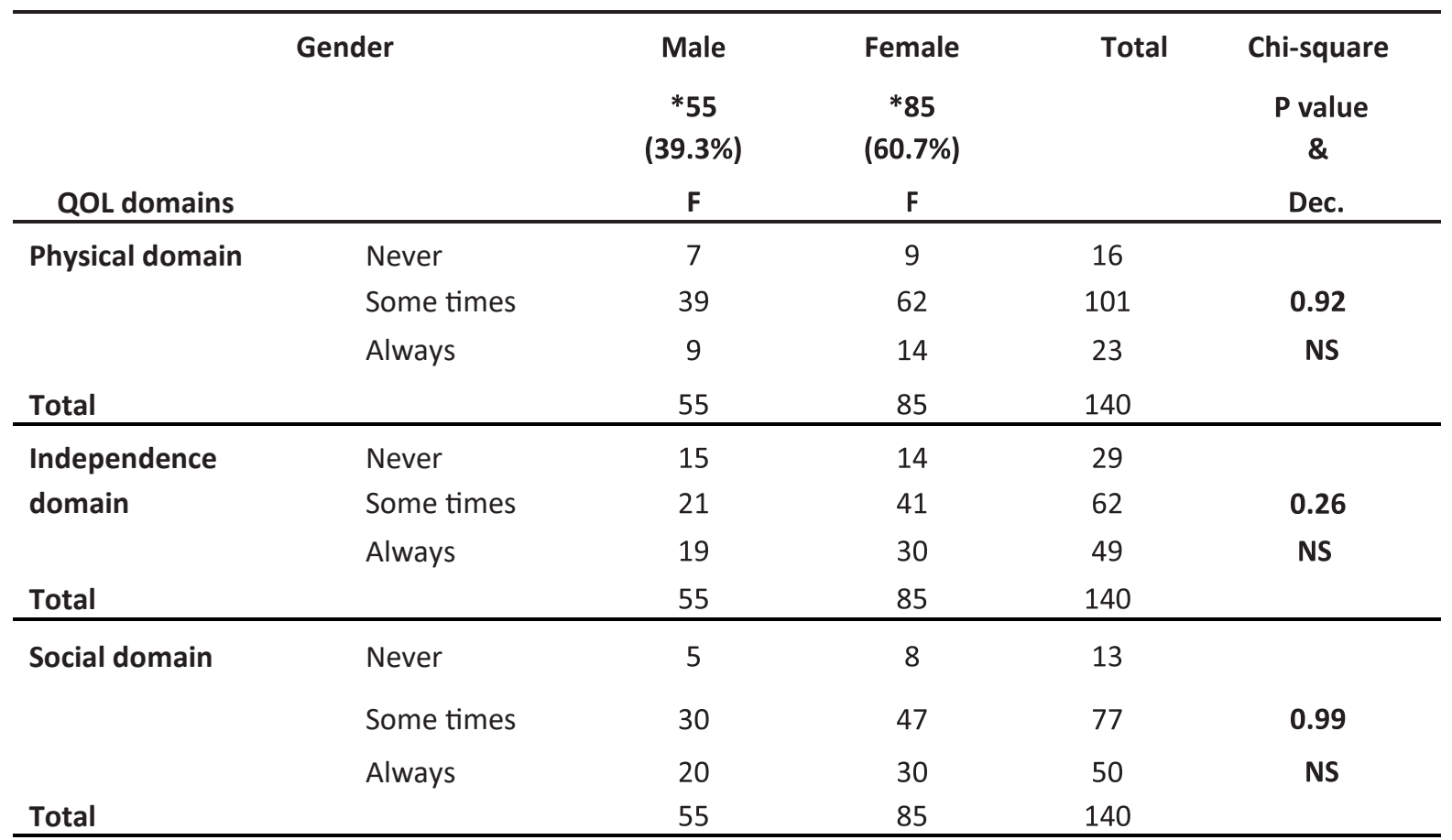

NS: Non-significant

Dec.: Decision

Table .5 Associations between patients' level of education and QOL domains of heart failure patients

\begin{tabular}{|c|c|c|c|c|c|c|c|c|}
\hline \multicolumn{2}{|c|}{ Educational level } & \multirow{2}{*}{$\begin{array}{c}\text { Illiterate } \\
\\
{ }^{* 102} \\
(72.8 \%)\end{array}$} & \multirow{2}{*}{$\begin{array}{l}\text { Able to } \\
\text { read and } \\
\text { write } \\
{ }^{*} 21 \\
(15 \%)\end{array}$} & \multirow{2}{*}{$\begin{array}{l}\text { Primary } \\
\text { school } \\
\text { graduate } \\
* 11 \\
(7.9 \%)\end{array}$} & \multirow{2}{*}{$\begin{array}{c}\text { Secondary } \\
\text { school } \\
\text { graduate } \\
* 4 \\
(2.9 \%)\end{array}$} & \multirow{2}{*}{$\begin{array}{c}\begin{array}{c}\text { College } \\
\text { graduate }\end{array} \\
{ }^{*} 2 \\
(1.4 \%)\end{array}$} & \multirow{2}{*}{ Total } & \multirow{3}{*}{$\begin{array}{l}\text { Chi-square } \\
\text { P-value } \\
\text { \& Dec. }\end{array}$} \\
\hline & & & & & & & & \\
\hline QOL domains & & $\mathbf{F}$ & $\mathbf{F}$ & $\mathbf{F}$ & $\mathbf{F}$ & $\mathbf{F}$ & $\mathbf{F}$ & \\
\hline Physical & Never & 10 & 1 & 4 & 1 & 0 & 16 & \\
\hline \multirow[t]{2}{*}{ domain } & Some times & 77 & 16 & 6 & 2 & 0 & 101 & 0.012 \\
\hline & Always & 15 & 4 & 1 & 1 & 2 & 23 & $S$ \\
\hline Total & & 102 & 21 & 11 & 4 & 2 & 140 & \\
\hline Independence & Never & 16 & 4 & 7 & 2 & 0 & 29 & \\
\hline \multirow[t]{2}{*}{ domain } & Some times & 48 & 12 & 1 & 0 & 1 & 62 & 0.009 \\
\hline & Always & 38 & 5 & 3 & 2 & 1 & 49 & VHS \\
\hline Total & & 102 & 21 & 11 & 4 & 2 & 140 & \\
\hline \multirow{3}{*}{$\begin{array}{l}\text { Social } \\
\text { domain }\end{array}$} & Never & 8 & 1 & 4 & 0 & 0 & 13 & \\
\hline & Some times & 59 & 11 & 5 & 2 & 0 & 77 & 0.05 \\
\hline & Always & 35 & 9 & 2 & 2 & 2 & 50 & $S$ \\
\hline Total & & 102 & 21 & 11 & 4 & 2 & 140 & \\
\hline S: Significant & VHS: Very H & hly Signif & & : Decision & & & & \\
\hline
\end{tabular}


Table 6. Association between patients'marital status and quality of life domains of heart failure patients

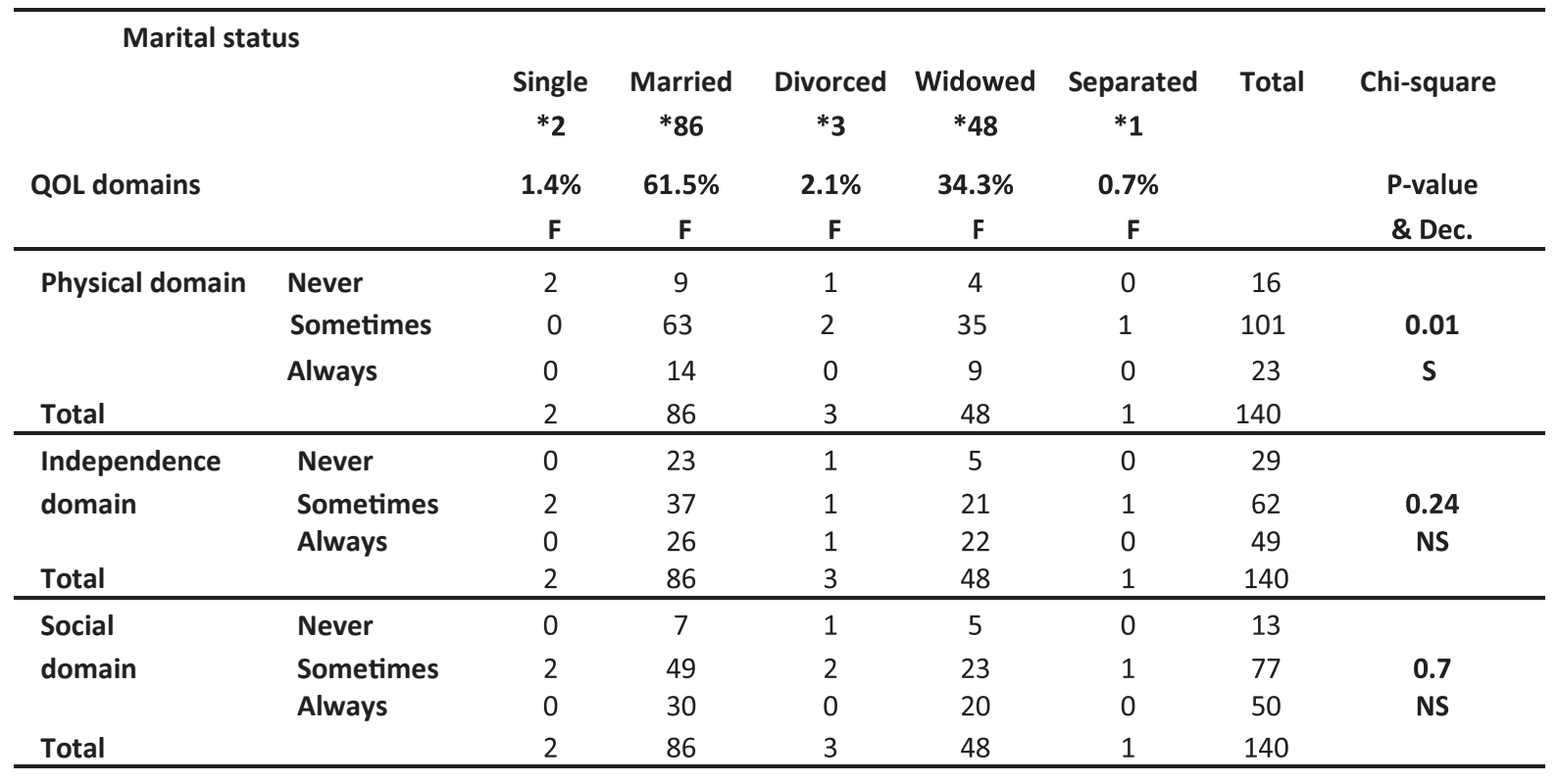

NS: Non-significant S: Significant DC: Decision

\section{DISCUSSION}

The result shows that most of the patients were in age group of $\geq 65$ years. This is similar to the cross-sectional study which carried out on 103 patients with Heart Failure in Brazil [15] and the majority of the patients in this study were females. This result is similar to the results of study which carried out in Tehran by Hatmi et al (2015) who found that most of the heart failure patients were female [16].Regarding levels of education, the present study revealed that majority of the patients $(72.8 \%)$ were illiterate. About the marital status, the majority of the patients were married, which was consistent with the result of study done by Dunlay et al (2015) on 1128 . The result of the study indicates that the highest percentage $(68.7 \%)$ of the patients' age was 65 years and more. It is in line with study done by Yaghoubi et al (2012) by increasing age significant decrease occur in patient's quality of life [19].Regarding association between gender and quality of life domains of HF patients, there was no significant association between gender and quality of life domains as shown in table 4, the result of study consistent with the study done by Erceg et al (2013) who found that there were no significant differences between male and female patients regarding health-related quality of life. Table 5 , shows that there was significant relationship between levels of education and physical domain, level of independence domain and social domain. The highest percentage of patients was illiterate. The study results were supported by Erceg et al (2013) who reported that the education level of the patients correlated positively with the physical dimension of healthrelated quality of life but not with emotional dimension[20]. The findings of the present study in table 6 shows there was a significant association between marital status and physical domain. While there was no significant association with level of independence and social domain. This is similar with the study carried out by Luttik et al (2006) who revealed that patients living with a partner had (12\%) less events 
compared with patients living alone [21].

\section{CONCLUSION}

Present study concluded that patients' quality of life was moderate level. The study recommends that further study to establish health educational program for patients and caregivers, designed to help heart failure patients live better or life longer. Integration quality of life in care plans and focusing on providing holistic care in heart failure patients in order to improve quality of life in long term.

\section{CONFLICT OF INTEREST}

The authors reported no conflict of interes

\section{REFERENCES}

[1] Boon, N.A., Colledge, N.R., Walker, B.R., and Hunter, A.J.A., editors (2006). Davidsons principles \& practice of medicine. $20^{\text {th }}$ ed. Philadelphia: Elsevier. P. 542.

[2] Carpenter, C.C., Griggs, R.C., and Benjamin, I.J., (2007). Andreoli and Carpenters Cecil Essential of Medicine. $7^{\text {th }}$ ed. Canada: Saunders and Elsevier. P.830

[3] Smeltzer, S.C., Bare, B.G., Hinkle, J.L., and Cheever, K.H., editors (2010). Brunner\& Suddarths Text book of Medical - Surgical Nursing. 12th ed. Philadelphia: Lippincott Williams and Wilkins. P. 825-830.

[4] Hoekstra,T. Jaarsma,T., Veldhuisen, D.J.,Hillege, H.L, Sanderma,R. and Leegte, I.L.Quality of life and survival in patients with heartfail Ure. European Journal of Heart Fail ure.2013;15(1):94-102.

[5] Braunwald, E., Kasper, D.L., Fauci, A.S., Hauser, S.L., Long, D.L., and Jameson, J.L., editors (2015). Harrison's principle of internal medicine. $16^{\text {th }}$ ed. New York: McGraw-Hill. P. 1367.

[6] Mozaffarian D, Go AS, Roger VL, Benjamin EJ, and Berry JD. Heart disease and stroke statistics-2013 update: a report from the American Heart Association.Circulation.2013;127 (1):e6-e245.
[7] Evangelista, L.S., Moser, D.K., Westlake, Ch., Pike,N., Ter-Galstanyan, A. and Dracup, K. Correlates of Fatigue in Patients With Heart Failure. Progress in Cardiovascular Nursing banner.2008;23(1):12-17.

[8] Lee, SH. Khurana, R, Gerard Leong, K.T. Heart failure: epidemiology and prevention in India. National Medical Journal India.2010;23 (5):283-288.

[9] Lewis, S.L., Heitkemper, M.M.,and Dirksen,S.R.Medical Surgical Nursing Assessment and Management of Clinical Problem. $7^{\text {th }}$ ed.(2007). Philadelphia: Mosby Elsevier. P.P821-822.

[10] Lemon, P.,and Burke, K.Medical SurgicalNursing Critical Thinking in Client Care. $4^{\text {th }}$ ed. USA:(2008) Person Education. P .1030.

[11] Timby, B.K., and Smith, N.E .Introductory Medical Surgical Nnursing.10 $10^{\text {th }}$ ed.China: (2010) Lippincott Williams and Wilkins. P.392.

[12] Coelho,R., Ramos,S., Prata,J., Bettencourt,P.,Ferreira,A., and Gomes,M.,C. Heart failure and health related quality of life. Clinical Practice and Epidemiology in Mental Health.2005;1(19).

[13] Papadopoulou, E. F., Mavrogeni, S. I., Dritsas, A., and Cokkinos D. V. Assessment of Quality of Life Using Three Activity Questionnaires in Heart Failure Patients After Monthly, Intermittent Administration of Levosimendan During a Six-Month Period. Hellenic Journal Cardiology.2009;50(4):269-274.

[14] Karapolat, H., Eyigor, S., Zoghi, M., Nalbantgil,S., Yagdi, T., Durmaz, B. et al. Health related quality of life in patients awaiting heart transplantation. The Tohoku Journal of Experimental Medicine.2008;214(1):17-25.

[15] Pena, F.M., Soares, J.S., Paiva, B.T.C.,Piraciaba, M.C.T., Marins, R.M., Barcellos,A.F et al. Sociodemographic factors and depressive symptoms in hospitalized patients with heart failure. Experimental and Clinical Cardiology. 2010; 15(2) : e29-e32.

[16] Hatmi, Z.N., Shaterian, M. and Kazemi, M.A. Quality of life in patiens hospitalized with heart failure:Anovel two questionnaire study .Acta Medica Iranica.(2007) .45(6): 493 $-500 ; 2007$

[17] Dunlay, Sh.M. Manemann, Sh.M., Chamberlain,A.M., Cheville,A.L., Jiang, R., Weston,S.A., et al. Activities of Daily Living and Outcomes in Heart Failure. Circulation Heart Failure.2015;8:261-267 
[18] Wu, J.R., Moser, D.K., Rayens, M.K., Jong, M.J.D., Chung, M.L., Riegel, B., et al. Rurality and Event-free Survival in Patients with Heart Failure. Heart Lung.2010;39(6):5125200.

[19] Yaghoubi, A., Tabrizi, J.S., Mirinazhad, M.M., Azami, S., M.N.,Behzad, Ghojazadeh, M. Quality of Life in Cardiovascular Patients in Iran and Factors Affecting It: A Systematic Review. Journal of Cardiovascular and Thoracic Research.2012;4(4):95-101.

[20] Erceg, P., Despotovic, N., Milosevic, P. D., Soldatovic, I., Zdravkovic, S., Tomic, S., et al. Health-related quality of life in elderly patients hospitalized with chronic heart failure. Clinical Interventions in Aging.2013;8:153946.

[21] Luttik, M.L., Jaarsma, T., Veeger, N. and Veldhuisen, D.J. Marital status, quality of life, and clinical outcome in patients with heart failure. Heart Lung.2006;35(1):3-8. 